\title{
Neural responses to the production and comprehension of syntax in identical utterances
}

\author{
Peter Indefrey, ${ }^{\mathrm{a}, \mathrm{d}, *}$ Frauke Hellwig, ${ }^{\mathrm{a}, \mathrm{d}}$ Hans Herzog, ${ }^{\mathrm{b}}$ Rüdiger J. Seitz, ${ }^{\mathrm{c}}$ and Peter Hagoort ${ }^{\mathrm{d}}$ \\ a Max Planck Institute for Psycholinguistics, Postbus 310 Nijmegen NL-6500, The Netherlands \\ ${ }^{\mathrm{b}}$ Institute of Medicine, Research Center Jülich, Germany \\ ${ }^{\mathrm{c}}$ Department of Neurology, University of Düsseldorf, Germany \\ ${ }^{\mathrm{d}}$ F.C. Donders Centre for Cognitive Neuroimaging, Nijmegen, The Netherlands
}

Accepted 21 August 2003

\begin{abstract}
Following up on an earlier positron emission tomography (PET) experiment (Indefrey et al., 2001), we used a scene description paradigm to investigate whether a posterior inferior frontal region subserving syntactic encoding for speaking is also involved in syntactic parsing during listening. In the language production part of the experiment, subjects described visually presented scenes using either sentences, sequences of noun phrases, or sequences of syntactically unrelated words. In the language comprehension part of the experiment, subjects were auditorily presented with the same kinds of utterances and judged whether they matched the visual scenes. We were able to replicate the previous finding of a region in caudal Broca's area that is sensitive to the complexity of syntactic encoding in language production. In language comprehension, no hemodynamic activation differences due to syntactic complexity were found. Given that correct performance in the judgment task did not require syntactic processing of the auditory stimuli, the results suggest that the degree to which listeners recruit syntactic processing resources in language comprehension may be a function of the syntactic demands of the task or the stimulus material.
\end{abstract}

(C) 2003 Elsevier Inc. All rights reserved.

Keywords: Positron emission tomography; Syntax; Language; Speech

\section{Introduction}

It is a long standing issue in psycholinguistics whether syntactic encoding in language production and syntactic parsing in language comprehension are performed by different processors or by a single processor (Frazier, 1982; Garrett, 1982; Jackendorff, 1987; Kempen, 2000). In principle, the anatomical comparison of hemodynamic brain activations in sentence production and comprehension can provide evidence in favour of common or distinct neural substrates of syntactic encoding and parsing. Such data might indirectly support single or dual processor architectures of syntactic processing. Indefrey et al. (2001) introduced a paradigm for the elicitation of naturally produced responses with different degrees of syntactic encoding but constant and limited

\footnotetext{
${ }^{*}$ Corresponding author. Fax: +31-24-3521-335

E-mail address: indefrey@mpi.nl (P. Indefrey).
}

conceptual processing demands. They found the left Rolandic operculum, caudally adjacent and in part overlapping with Brodmann area (BA) 44 to be sensitive to the syntactic complexity of the utterances that subjects produced to describe visual scenes. Activations of the opercular part of the left inferior frontal gyrus, next to the Rolandic operculum, have also been found in hemodynamic studies of syntactic comprehension (Dapretto \& Bookheimer, 1999; Embick, Marantz, Miyashita, O'Neil, \& Sakai, 2000; Friederici, Meyer, \& von Cramon, 2000; Kang, Constable, Gore, \& Avrutin, 1999; Stromswold, Caplan, Alpert, \& Rauch, 1996). While this might be taken as support for the notion of a common syntactic processor, other locations reported for syntactic comprehension are several centimeters away (Caplan, Alpert, \& Waters, 1998, 1999; Caplan, Alpert, Waters, \& Olivieri, 2000) or not in the frontal lobe at all (see reports on temporal lobe activations by Embick et al., 2000; Friederici et al., 2000; Just, 
Carpenter, Keller, Eddy, \& Thulborn, 1996; Mazoyer et al., 1993; Meyer, Friederici, \& von Cramon, 2000; Ni et al., 2000; Stowe et al., 1998). The exact locations of hemodynamic activations related to syntactic processing seem to depend on the experimental tasks, control conditions, and the input modality (for overviews see Friederici, 2002; Indefrey, 2003; Kaan \& Swaab, 2002). Even with very similar tasks there are considerable differences in the exact locations of the resulting activation areas (Caplan et al., 1998, 1999, 2000; Stromswold et al., 1996) that are probably at least in part due to the anatomical variability between subjects. Between-study comparisons are, therefore, of limited value when trying to answer the question of a single versus dual architecture of the syntactic processing system. To rule out most of the confounding factors, we compare in this study the production and the comprehension of identical utterances of varying syntactic complexity.

\section{Materials and methods}

\subsection{Subjects}

Eighteen (eight females and 10 males) native speakers of German in the age range of 20-36 (mean age 25.8 years) participated in the experiment. All were consistent right-handers (Oldfield, 1971) in good health and gave written informed consent in accordance with the Declaration of Helsinki. The study was approved by the Ethics Committee of the Heinrich-Heine-University Düsseldorf.

\subsection{Tasks}

In the production part of the experiment, subjects viewed animated scenes and described them in different conditions in three different prespecified ways: (i) in a full sentence (S), (ii) with a sequence of noun phrases followed by the main verb in the infinitive form (NP), or (iii) with a sequence of single words having no syntactic relationship (W). Fig. 1 shows examples of three frames of one animated scene and of the different descriptions in German that were required of the subjects in different blocks. In order to minimize conceptual and naming ambiguities, the animated scenes did not involve people performing actions, but a fixed set of three colored twodimensional geometric objects. These objects could perform two specific actions upon one another: to go next to another object ("daneben gehen"), or to set another object in motion by impact ("wegstoßen"). The objects were a circle ("der Kreis"-masculine gender), an ellipse ("die Ellipse"-feminine gender) and a square ("das Viereck"-neuter gender). The three colors were red, blue, and green. Color assignment to objects varied randomly. In order to make naming of color plus shape the most natural description, there were always two objects that could only be distinguished by their color. The actions were performed by one or two of the objects. Subjects were instructed to name all participants of an action, their respective colors, and the action itself. In all response conditions, the order in which the objects were to be named depended on their role in the action (i.e., whether they themselves acted or were acted upon). This ensured equal conceptual processing of the scenes across conditions. The subjects were asked to press a pushbutton after they had finished their utterance.

In the comprehension part of the experiment, the subjects viewed the same kind of scenes and were auditorily presented with the three types of utterances described above, spoken by a male voice. The utterances were followed by a signal tone. To ensure attentive listening, the subjects were instructed to indicate by a buttonpress after the tone, whether the utterances matched the visual scenes. Mismatching utterances were constructed such that they contained the same types of nonsyntactic errors in all three conditions. They were created by reverting the semantic roles, assigning a wrong color to an object, or using a verb that denoted the wrong action. Mismatching uttererances occurred in one sixth of the trials but not during the sampling period of the $\mathrm{PET}^{1}$ scan.

Participants were trained on the task one week before PET measurement. Training began by introducing the objects and the actions. After being instructed on how to describe the scenes in the different response conditions, subjects practised each response condition in two blocks of 24 scenes, using the same stimuli as during PET measurement, but in a different order.

\subsection{Experimental procedures}

On each trial, an animated scene was presented for $1660 \mathrm{~ms}$ in the center of a Digital VT340 monitor screen, subtending a visual angle of $8^{\circ}$ both vertically and horizontally. The resulting configuration of the geometrical objects remained on the screen until subjects pressed the pushbutton. Stimulus presentation began approximately $60 \mathrm{~s}$ prior to PET scanning and lasted for $3 \mathrm{~min}$. During this time on average 21 scenes were presented. We applied two different presentation rates (eight scenes per minute and six scenes per minute) to control for the non-syntactic (lexical, phonological, phonetic, and articulatory) processing load of the additional grammatical markers that subjects produced or perceived in the sentence and noun phrase conditions. The increase of the overall language production rate (number of syllables per scanning period) that was induced by the fast presentation rate compared to the slow presentation rate was the same as that in the sentence

\footnotetext{
${ }^{1}$ Abbreviations used: PET, positron emission tomography; $\mathrm{rCBF}$, regional cerebral blood flow; BA, Brodmann area.
} 
(1)

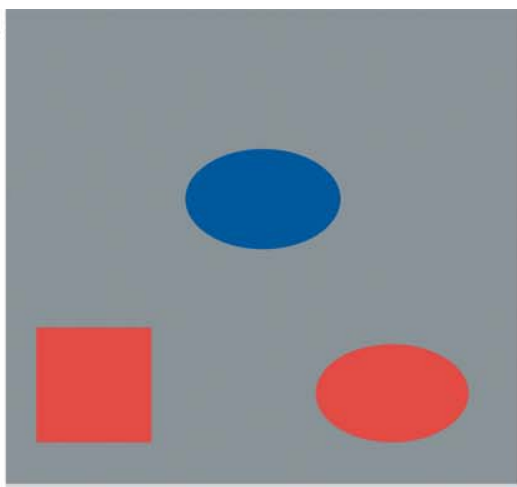

(S):

(NP):

(W):

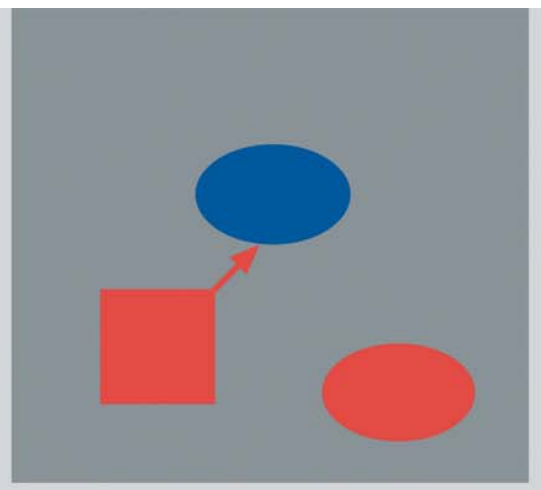

"Das rote Viereck stößt die blaue Ellipse weg."

(The red square launches the blue ellipse.)

"rotes Viereck, blaue Ellipse, wegstoßen"

(red square, blue ellipse, launch)

"Viereck, rot, Ellipse, blau, wegstoßen"

(square, red, ellipse, blue, launch)

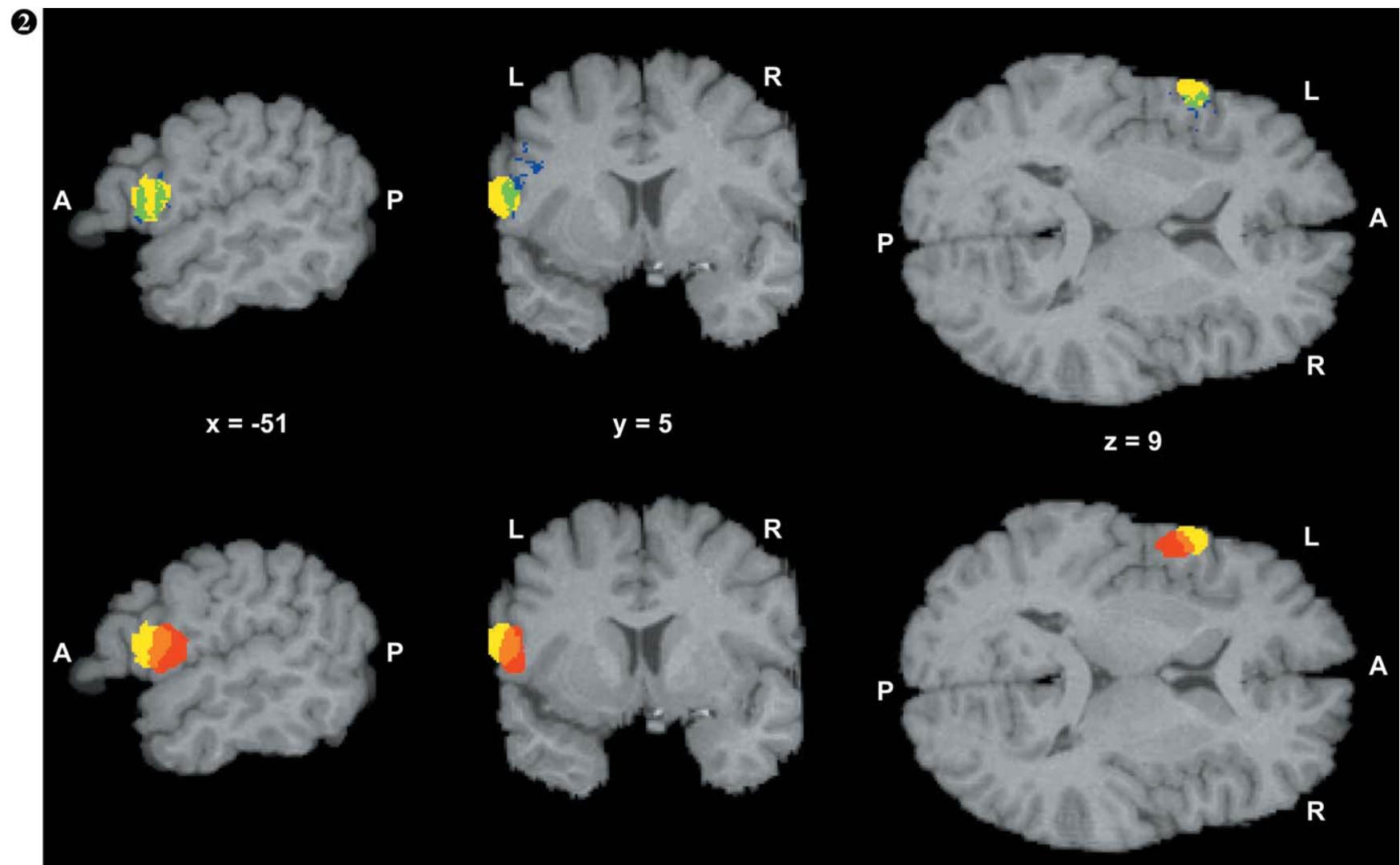

"The red square launches the blue ellipse." vs. "square red, ellipse blue, launch" 
condition compared to the single word condition. Therefore, possible hemodynamic effects due to differences in the overall language production rate between the sentence condition and the single word condition could be assessed by comparing the faster presentation rate to the slower presentation rate.

Twelve PET scans per subject were performed. The conditions were in the order $\mathrm{ABCABCABCABC}$; the assignment of sentence, noun phrase, and single word conditions to the positions $\mathrm{A}, \mathrm{B}$, and $\mathrm{C}$ was balanced across subjects. Production and comprehension changed every three scans. Half of the subjects began with production, the other half with comprehension. The visual stimuli were presented in a fixed order that was reversed for half of the subjects. The presentation rate changed after half of the scans; half of the subjects started with the slower rate, the other half with the faster rate.

\subsection{PET data acquisition and analysis}

PET data were recorded with a CTI EXACT HR+ PET camera. Scanning started at the time of intravenous injection of the tracer into the right brachial vein. Reconstructed activity images comprised a period of $40 \mathrm{~s}$ starting with tracer arrival in the brain. For each scan, approximately $550 \mathrm{MBq}\left[{ }^{15} \mathrm{O}\right]$ butanol was injected as a bolus. A combined dynamic-autoradiographic approach (Herzog et al., 1996) delivered image volumes of quantitative regional cerebral blood flow (rCBF).

To ensure the comparability of results, the data analysis was performed exactly as in Indefrey et al. (2001). We used the statistical parametric mapping (SPM96) software provided by the Wellcome Department of Cognitive Neurology, London (Friston et al., 1995). The image volumes were realigned, normalized into standard stereotactic space (using the template of the Montreal Neurological Institute provided by SPM96), smoothed with a $10 \mathrm{~mm}$ (full width at half maximum) Gaussian filter, and corrected for residual within- and betweensubject global cerebral blood flow variation by analysis of covariance. For statistical comparisons of activationcontrol contrasts, we chose a strict Bonferroni-corrected threshold of $P<.05$. Hypotheses about rCBF differences within a region of interest were tested by ANOVA and post-hoc $t$ tests for paired samples at a threshold of $P<.05$, corrected for number of comparisons.

\subsection{Anatomical localization procedure}

Using the procedure of Indefrey et al. (2001), we compared the functional activation focus to the cytoarchitectonic location of BA 44 defined as the overlap of BA 44 of at least five of 10 post-mortem brains as described in Amunts et al. (1999). For the projection of functional data onto the same reference brain, we mapped the brain template of the Montreal Neurological Institute to the template of the European Computerized Human Brain Database (Roland \& Zilles, 1996) by means of the anatomical standardization procedure of SPM96, and applied the resulting transformation parameters to the statistical parametric maps. The resulting positions of the functional activations relative to anatomical landmarks were unchanged.

\section{Results}

\subsection{Behavioral data}

In the production conditions, response utterances were recorded on Digital Audio Tape and analyzed for voice onset time (measured from the time at which the final configuration of geometrical shapes was reached) and response duration by means of the XWAVES speech-processing package. In four subjects we observed exceptionally long voice onset times and occasional accusative case marking in the noun phrase condition (e.g., "rote Ellipse, blauen Kreis, wegstoßen"), suggesting that they might have used a response strategy involving initial subvocal sentence production. These subjects were excluded from further analyses. Voice onset times for the remaining 14 subjects were $1527 \mathrm{~ms}$ (SD $204 \mathrm{~ms}$ ) for sentences, $1554 \mathrm{~ms}$ ( $S D \quad 172 \mathrm{~ms}$ ) for noun phrases, and $1500 \mathrm{~ms}$ (SD $162 \mathrm{~ms}$ ) for single words. Response

Fig. 1. Example of an animated stimulus scene. In this scene the red square launches the blue ellipse. Arrows are added to indicate the movement direction of the objects on the computer screen. Stimuli of the same kind were used in all three conditions. Examples of the three response types are given below ( $\mathrm{S}$, sentence condition; NP, noun phrase condition; and W, single word condition). The response types differed in the degree of syntactic encoding and the corresponding application of grammatical markers (printed in bold) in German. Local gender agreement marking on the adjective was required in noun phrase and sentence responses but not in the single word responses. Only in the sentence condition syntactic relations across several words had to be expressed by means of word order and inflection of the main verb.

Fig. 2. Cortical activation of the production of sentence relative to single word utterances. The maximally activated voxel was located at $x=-60$, $y=14$, and $z=12$ (coordinates as given by SPM96. Note that the depicted sagittal section is taken more medially to improve the visibility of the anatomical configurations of the posterior inferior frontal gyrus). Significantly activated voxels are projected in yellow onto anatomical MR sections of a reference brain. Upper panel for anatomical comparison, voxels belonging to BA 44 are projected in blue onto the same reference brain. The activated volume overlapped with $36.8 \%$ (shown in green) of the $50 \%$ probability area for left BA 44 . Lower panel comparison with a previous experiment with the same paradigm. Significantly activated voxels found in Indefrey et al. (2001) are projected in red onto the same reference brain. The volume of overlap (shown in orange) corresponded to $29 \%$ of the previous activation volume. 
durations were $3288 \mathrm{~ms}$ ( $S D 385 \mathrm{~ms}$ ) for sentences, $3465 \mathrm{~ms}$ ( $S D 396 \mathrm{~ms}$ ) for noun phrases, and $3404 \mathrm{~ms}$ ( $S D$ $380 \mathrm{~ms}$ ) for single words. A $3 \times 2$ ANOVA with the within-subject factors condition and response variable (with the levels voice onset time and response duration) showed a significant main effect of condition $(F=5.427$; $d f=2 ; P=.011)$ and a significant interaction of condition by response variable $(F=4.824 ; \quad d f=2$; $P=.017)$. Post-hoc $t$ tests showed significant differences between NP-onset and W-onset $(t=2.385 ; d f=13$; $P=.033$ ) and between S-duration and NP-duration $(t=2.953 ; d f=13 ; P=.011)$. In comprehension, all 14 subjects gave $99.99 \%$ correct responses.

\subsection{Regional cerebral blood flow data}

Comparing the $\mathrm{rCBF}$ data of the two production conditions that differed maximally in terms of syntactic encoding, i.e., sentences and isolated words, we found a single activation area $(Z=4.37, P=.038$ corrected $)$ in caudal Brodmann area 44, extending into the adjacent Rolandic operculum (see Fig. 2, upper panel). The ac- tivation maximum ( $x, y, z$-coordinates as given by SPM96 -60,14,12) was $6 \mathrm{~mm}$ more anterior, $8 \mathrm{~mm}$ more lateral, and $2 \mathrm{~mm}$ more dorsal than the one observed in Indefrey et al. (2001, see Fig. 2, lower panel). There was no significant activation in the reverse comparison.

To determine whether the activated area was sensitive to sentence-level syntactic processing only, or also responded to local syntactic processing on the noun phrase level, we compared the mean regional cerebral blood flow in this region of interest across all three conditions (see Fig. 3, leftmost three columns). Both sentences ( $t=3.793, d f=13, P=.002$, two-tailed) and noun phrases $(t=4.993, d f=13, P=.000$, two-tailed) activated this region more strongly than isolated words. There was no significant difference between sentences and noun phrases $(P>.1$, two-tailed $)$.

To determine whether the activated area was sensitive to syntactic processing only, or also responded to changes in the overall language production rate, we calculated a $3 \times 2$ ANOVA with the within-subject factors response condition and presentation rate on the mean regional cerebral blood flow data in this region of

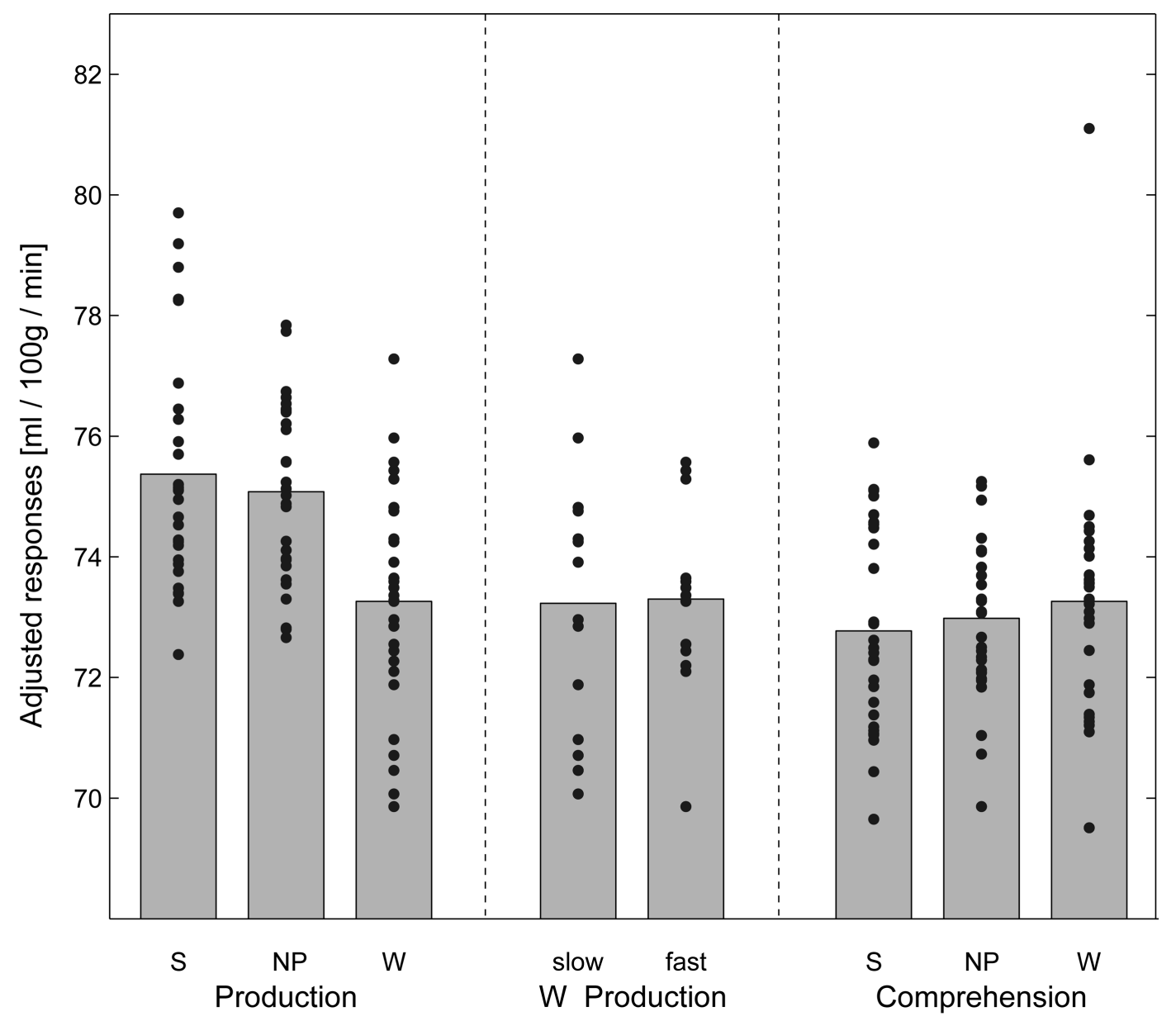

Fig. 3. Mean regional cerebral blood flow in the activated volume (Fig. 2) across conditions. Means are calculated for a region of interest comprising all 252 voxels $\left(2016 \mathrm{~mm}^{3}\right)$ that were significantly activated for the production of sentence relative to single word utterances (global cerebral blood flow adjusted to $50 \mathrm{ml} / 100 \mathrm{~g} / \mathrm{min}$; $\mathrm{S}$, sentence condition; $\mathrm{NP}$, noun phrase condition; and $\mathrm{W}$, single word condition). 
interest. There was a significant main effect $(F=11.715$, $d f=2, P=.000)$ of the factor condition. There was no significant main effect of the factor presentation rate $(P>.1)$ and no significant interaction of the two factors $(P>.1)$. A post-hoc $t$ test comparing the mean $\mathrm{rCBF}$ in the single word condition at faster versus slower stimulus presentation rates showed no significant difference ( $P>.1$, one tailed, see Fig. 3, middle two columns).

The analysis of blood flow data for the whole brain volume yielded no significant activation differences between $\mathrm{S}, \mathrm{NP}$, and $\mathrm{W}$ conditions in comprehension. There was also no significant difference in a ROI analysis for the volume that was more strongly activated in $\mathrm{S}$ versus W production (see Fig. 3, rightmost three columns). A conjunction analysis comparing production and comprehension across conditions showed extensive bilateral motor cortex $(x, y, z=-56,-2,28 ; 60,-14,40)$, supplementary motor area SMA; $x, y, z=-4,2,56$, and cerebellar $(x, y, z=14,-56,-10 ;-14,-60,-8)$ activation areas. The reverse comparison showed extensive bilateral temporal $(x, y, z=-58,-36,10 ; 52,-2,-10)$ and temporoparietal $(x, y, z=-50,-48,34 ; 54,-52,34)$ activation areas as well as a right superior frontal gyrus activation $(x, y, z=10,30,50)$.

\section{Discussion}

In this study, we investigated the cerebral activation during the production and the comprehension of utterances that varied in syntactic complexity. To study the hemodynamic responses to syntactic encoding during speaking, we used a scene description paradigm with a constant conceptual processing load that was introduced by Indefrey et al. (2001). To study syntactic parsing during listening to speech, we modified the paradigm such that the scene descriptions were not produced by the subjects but auditorily presented. We did not alter the visual stimuli or the corresponding descriptions, except for trials with mismatching descriptions that occurred before and after the data sampling period of the PET scans.

The stronger activation of motor-related areas that was observed in the overall comparison of production conditions with comprehension conditions was expected, since the subjects performed articulatory movements during the production scans but not during the comprehension scans. Given that subjects had to attend to the auditory stimuli in the comprehension conditions but not to their own voice in the production conditions, we also expected stronger bilateral temporal activations in the comprehension conditions compared to the production conditions.

The results of the production part of the experiment replicated the findings of Indefrey et al. (2001). There was a single region in caudal Broca's area (BA 44) and the adjacent Rolandic operculum that was more strongly activated during the production of sentences and noun phrases compared to the production of syntactically unrelated words. Taking into account that this region was not sensitive to an increased non-syntactic processing load (higher versus lower stimulus presentation rate in the word condition), the finding indicates that this region is most probably involved in some aspect of syntactic encoding. In the previous study, the hemodynamic response during sentence production was stronger than during noun phrase production suggesting that caudal Broca's area subserves sentence-level syntactic encoding in addition to the local, phrase-level syntactic encoding required in both conditions. In the present study there was a trend in the same direction, but no significant difference, so that this conclusion is less strongly supported. Some evidence as to the possible role of Broca's area in syntactic production comes from a recent picture-naming study by Heim, Opitz, and Friederici (2002), in which BA 44 was activated when subjects produced gender-marked determiners as compared to pure noun responses. Although this finding points to an involvement of Broca's area in the retrieval or selection of morphosyntactic features rather than in syntactic structure building, it should be noted that an involvement of structure building processes in the activation reported by Heim et al. (2002) cannot be excluded since subjects possibly produced full determiner phrases (determiner plus noun) subvocally. Furthermore, the reported activation maximum was about $1 \mathrm{~cm}$ more dorsal and medial than the maximum of the activation area reported here.

Compared to the previous study, the activation focus was shifted several millimeters anteriorly and laterally. Given that we used exactly the same paradigm and data analysis, including anatomical standardization procedures, this result is most probably due to the anatomical variability between subjects and may serve as an indicator of the degree of anatomical reliability to be expected in hemodynamic activations of the left inferior frontal gyrus. The result does not permit a distinction between subject variability in terms of the location of macroscopic or cytoarchitectonic anatomical structures, which may lead to a different mapping onto the template brain, and subject variability in terms of the anatomical substrate of the syntactic processing function.

We failed to detect any region that was sensitive to syntactic complexity in comprehension. Of four other studies comparing auditorily presented syntactically correct sentences to word lists (Friederici et al., 2000; Kuperberg et al., 2000; Wong, Miyamoto, Pisoni, Sehgal, \& Hutchins, 1999; Wong et al., 2002) one study (Wong et al., 1999) found a left inferior frontal gyrus activation (BA 47). The other three report left or bilateral temporal activation areas. The negative result 
obtained in the present study is most probably due to our specific materials and tasks. One possible explanation is based on the fact that the sentences we used were syntactically relatively simple. Using a comprehension task, Cooke et al. (2002) observed significant left posterior inferior frontal activation only for syntactically complex sentences with long antecedent-gap distances but not for less demanding sentences. The authors interpret this finding in terms of a particular role of Broca's area for the processing of long-distance antecedent-gap relationships (see Grodzinsky, 2000; with a similar suggestion based on clinical data). Following this interpretation, the results of the present study would require the assumption of separate syntactic processors for comprehension and production in Broca's area, since the sentences that activated Broca's area in production were syntactically identical to the sentences that failed to activate it in comprehension. Such far-reaching theoretical consequences, however, are not warranted by our findings, which can also be accounted for in terms of a task-induced strategic effect. To ensure that the mismatch detection could be performed alike in all three conditions, the mismatches had to be detectable by comparing the visual scenes with the meanings of the words in the corresponding utterances. This property of the experimental material was, therefore, a strong incentive for the subjects to use a lexical semantic strategy for solving the task. It has been demonstrated that this kind of strategic manipulation can affect hemodynamic responses. Dapretto and Bookheimer (1999) found the activation level of Broca's area to be reduced when subjects performed a semantic compared to a syntactic task on stimulus sentences of comparable syntactic complexity. Friederici et al. (2000) found that pseudoword sentences activated bilateral inferior frontal and superior temporal areas more strongly than normal prose sentences with the same syntactic structure. In a recent review article, Kaan and Swaab (2002) suggest that these kinds of meaningless sentences "lack semantic cues and, hence, might engage the syntactic system to a greater extent." In addition to these studies, in which the degree of the recruitment of syntactic processing resources was temporarily altered by the experimental task, recent ERP data suggest that in the presence of permanent syntactic processing problems, as in agrammatic aphasia, comprehension is attempted by a stronger focus on semantic processing routines (Hagoort, Wassenaar, \& Brown, 2003).

In sum, our data show that for sentences with identical syntactic structures the activation of Broca's area may greatly differ between production and comprehension. While syntactic encoding is inevitable for grammatically correct speaking, listeners engage in syntactic processing and recruit the corresponding neural structures to a varying extent depending on their processing resources and the task demands.

\section{Acknowledgments}

The authors wish to thank Katrin Amunts for providing the cytoarchitectonic probability maps of Brodmann areas 44 and 45. Peter Indefrey and Frauke Hellwig were in part supported by the Human Frontier Science Program Grant RG148/2000-B.

\section{References}

Amunts, K., Schleicher, A., Bürgel, U., Mohlberg, H., Uylings, H. B. M., \& Zilles, K. (1999). Broca's region revisited: Cytoarchitecture and intersubject variability. Journal of Comparative Neurology, 412, 319-341.

Caplan, D., Alpert, N., \& Waters, G. (1998). Effects of syntactic structure and propositional number on patterns of regional cerebral blood flow. Journal of Cognitive Neuroscience, 10, 541552.

Caplan, D., Alpert, N., \& Waters, G. (1999). PET studies of syntactic processing with auditory sentence presentation. Neuroimage, 9 , 343-351.

Caplan, D., Alpert, N., Waters, G., \& Olivieri, A. (2000). Activation of Broca's area by syntactic processing under conditions of concurrent articulation. Human Brain Mapping, 9, 65-71.

Cooke, A., Zurif, E. B., DeVita, C., Alsop, D., Koenig, P., Detre, J., Gee, J., Piñango, M., Balogh, J., \& Grossman, M. (2002). Neural basis for sentence comprehension: Grammatical and short-term memory components. Human Brain Mapping, 15, 80-94.

Dapretto, M., \& Bookheimer, S. Y. (1999). Form and content: Dissociating syntax and semantics in sentence comprehension. Neuron, 24, 427-432.

Embick, D., Marantz, A., Miyashita, Y., O’Neil, W., \& Sakai, K. L. (2000). A syntactic specialization for Broca's area. Proceedings of the National Academy of Sciences of the United States of America, 97, 6150-6154.

Frazier, L. (1982). Shared components of production and perception. In M. A. Arbib, D. Caplan, \& J. C. Marshall (Eds.), Neural models of language processing (pp. 225-236). New York: Academic Press.

Friederici, A. D. (2002). Towards a neural basis of auditory sentence processing. Trends in Cognitive Sciences, 6, 78-84.

Friederici, A. D., Meyer, M., \& von Cramon, D. Y. (2000). Auditory language comprehension: An event-related fMRI study on the processing of syntactic and lexical information. Brain and Language, 74, 289-300.

Friston, K. J., Holmes, A. P., Worsley, K. J., Poline, J.-B., Frith, C. D., \& Frackowiak, R. S. J. (1995). Statistical parametric maps in functional imaging - a general linear approach. Human Brain Mapping, 2, 189-210.

Garrett, M. F. (1982). Remarks on the relation between language production and comprehension systems. In M. A. Arbib, D. Caplan, \& J. C. Marshall (Eds.), Neural models of language processing (pp. 209-224). New York: Academic Press.

Grodzinsky, Y. (2000). The neurology of syntax: Language use without Broca's area. Behavioral and Brain Sciences, 23, 1-21.

Hagoort, P., Wassenaar, M., \& Brown, C. (2003). Real-time semantic compensation in patients with agrammatic comprehension: Electrophysiological evidence for multiple-route plasticity. Proceedings of the National Academy of Sciences of the United States of America, 100, 4340-4345.

Heim, S., Opitz, B., \& Friederici, A. D. (2002). Broca's area in the human brain is involved in the selection of grammatical gender for language production: Evidence from event-related functional magnetic resonance imaging. Neuroscience Letters, 328, 101-104. 
Herzog, H., Seitz, R. J., Tellmann, L., Kops, E. R., Julicher, F., Schlaug, G., Kleinschmidt, A., \& Müller-Gärtner, H. W. (1996). Quantitation of regional cerebral blood flow with O-15-butanol and positron emission tomography in humans. Journal of Cerebral Blood Flow and Metabolism, 16, 645-649.

Indefrey, P. (2003). Hirnaktivierungen bei syntaktischer Sprachverarbeitung: Eine Meta-Analyse. In G. M. Rickheit \& H.M. Müller (Eds.), Neurokognition in der Sprache. Stauffenburg Verlag, Tübingen.

Indefrey, P., Brown, C. M., Hellwig, F., Amunts, K., Herzog, H., Seitz, R. J., \& Hagoort, P. (2001). A neural correlate of syntactic encoding during speech production. Proceedings of the National Academy of Sciences of the United States of America, 98, 59335936.

Jackendorff, R. (1987). Consciousness and the computional mind. Cambridge, MA: MIT Press.

Just, M. A., Carpenter, P. A., Keller, T. A., Eddy, W. F., \& Thulborn, K. R. (1996). Brain activation modulated by sentence comprehension. Science, 274, 114-116.

Kaan, E., \& Swaab, T. Y. (2002). The brain circuitry of syntactic comprehension. Trends in Cognitive Sciences, 6, 350-356.

Kang, A. M., Constable, R. T., Gore, J. C., \& Avrutin, S. (1999). An event-related fMRI study of implicit phrase-level syntactic and semantic processing. Neuroimage, 10, 555-561.

Kempen, G. (2000). Could grammatical encoding and grammatical decoding be subserved by the same processing module? Behavioral and Brain Sciences, 23, 38-39.

Kuperberg, G. R., McGuire, P. K., Bullmore, E. T., Brammer, M. J., Rabe-Hesketh, S., Wright, I. C., Lythgoe, D. J., Williams, S. C. R., \& David, A. S. (2000). Common and distinct neural substrates for pragmatic, semantic, and syntactic processing of spoken sentences: An fMRI study. Journal of Cognitive Neuroscience, $12,321-341$.
Mazoyer, B. M., Tzourio, N., Frak, V., Syrota, A., Murayama, N., Levrier, O., Salamon, G., Dehaene, S., Cohen, L., \& Mehler, J. (1993). The cortical representation of speech. Journal of Cognitive Neuroscience, 5, 467-479.

Meyer, M., Friederici, A. D., \& von Cramon, D. Y. (2000). Neurocognition of auditory sentence comprehension: Event related fMRI reveals sensitivity to syntactic violations and task demands. Cognitive Brain Research, 9, 19-33.

Ni, W., Constable, R. T., Mencl, W. E., Pugh, K. R., Fulbright, R. K., Shaywitz, S. E., Shaywitz, B. A., Gore, J. C., \& Shankweiler, D. (2000). An event-related neuroimaging study distinguishing form and content in sentence processing. Journal of Cognitive Neuroscience, 12, 120-133.

Oldfield, R. C. (1971). The assessment and analysis of handedness: The Edinburgh inventory. Neuropsychologia, 9, 97-113.

Roland, P. E., \& Zilles, K. (1996). The developing European computerized human brain database for all imaging modalities. Neuroimage, 4, S39-S47.

Stowe, L. A., Broere, C. A. J., Paans, A. M. J., Wijers, A. A., Mulder, G., Vaalburg, W., \& Zwarts, F. (1998). Localizing components of a complex task: Sentence processing and working memory. Neuroreport, 9, 2995-2999.

Stromswold, K., Caplan, D., Alpert, N., \& Rauch, S. (1996). Localization of syntactic comprehension by positron emission tomography. Brain and Language, 52, 452-473.

Wong, D., Miyamoto, R. T., Pisoni, D. B., Sehgal, M., \& Hutchins, G. D. (1999). PET imaging of cochlear-implant and normal-hearing subjects listening to speech and nonspeech. Hearing Research, 132, $34-42$.

Wong, D., Pisoni, D. B., Learn, J., Gandour, J. T., Miyamoto, R. T., \& Hutchins, G. D. (2002). PET imaging of differential cortical activation by monaural speech and nonspeech stimuli. Hearing Research, 166, 9-23. 